\title{
Microsatellite analysis of the DCC gene in nephroblastomas: pathologic correlations and prognostic implications
}

\author{
Amsha Ramburan ${ }^{1}$, Runjan Chetty ${ }^{1}$, GP Hadley², Richard Naidoo ${ }^{3}$ and Dhirendra \\ Govender $^{1}$ \\ ${ }^{1}$ Department of Pathology, ${ }^{2}$ Department of Paediatric Surgery and ${ }^{3}$ Molecular Biology Research Facility, \\ Nelson R Mandela School of Medicine, University of Natal, Durban, South Africa
}

\begin{abstract}
Microsatellite instability has been reported in a wide variety of cancer types. Inactivation or loss of tumour suppressor genes has been shown to result in cell cycle deregulation and neoplastic growth. We conducted a microsatellite study using fluorescent-based DNA technology to determine whether mutations in the microsatellite sequences of the deleted in colorectal cancer $(D C C)$ gene, a tumour suppressor at 18q21.1, have any pathologic correlation or prognostic significance in nephroblastomas. Normal and tumour DNA was isolated from 106 cases of nephroblastoma using the standard proteinase $\mathrm{K}$ digestion and phenol-chloroform extraction method from paraffin wax-embedded tissue. Polymerase chain reaction using three microsatellite markers; D18S21, D18S34 and D18S58, for the DCC gene were performed. The polymerase chain reaction products were analysed on the ALF Express Automated DNA sequencer. The results were correlated with age at diagnosis, preoperative chemotherapy, clinicopathological stage, histological classification and patient outcome using $\chi^{2}$ test. Allelic imbalance/loss of heterozygosity appeared to be a more frequent genetic aberration than microsatellite instability with $20 \%$ of cases showing allelic imbalance/loss of heterozygosity and only $9 \%$ of cases showing microsatellite instability. Genetic aberrations were more frequent in unfavourable histology tumours compared to favourable histology tumours $(P=0.012)$. All patients with genetic aberrations for more than one $D C C$ marker died independent of histological classification and stage $(P=0.016)$. There was no statistically significant difference when $D C C$ aberrations were compared with age at diagnosis, preoperative chemotherapy and clinicopathological stage. In conclusion, this study has found that multiple aberrations involving the DCC locus may play a role in the progression of nephroblastomas, and hence confer a poorer prognosis

Modern Pathology (2004) 17, 89-95, advance online publication, 19 November 2003; doi:10.1038/modpathol.3800022
\end{abstract}

Keywords: DCC; microsatellites; nephroblastoma; prognosis

Deleted in colorectal cancer (DCC) is a tumour suppressor gene, at 18q21.1, that codes for a transmembrane protein that bears strong similarity to members of the superfamily of neural cell adhesion molecules. The DCC gene was originally identified in colorectal cancers where genetic alterations have been reported in $50 \%$ of large colorectal adenomas and in more than $70 \%$ of invasive colorectal carcinomas. ${ }^{1}$ Introduction of a normal chromosome 18 into human colorectal cancer cell lines suppressed tumorigenicity confirming $D C C$ 's function as a tumour suppressor gene.

Correspondence: A Ramburan, Department of Pathology, Nelson R Mandela School of Medicine, University of Natal, Private Bag 7, Congella, Durban 4013, South Africa.

E-mail: ramburana@nu.ac.za

Received 09 May 2003; revised 18 June 2003; accepted 18 August 2003; published online 19 November 2003
Mounting evidence suggests that DCC may be inactivated in several tumours arising outside the colon and rectum including epithelial tumours of the stomach, ${ }^{2}$ pancreas ${ }^{3}$ head and neck, ${ }^{4}$ breast,${ }^{5}$ prostate ${ }^{6}{ }^{6}$ oesophagus ${ }^{7}$ as well as in some leukaemias $^{8}$ and gliomas. ${ }^{9}$ Support for DCC inactivation in these tumours includes frequent loss of heterozygosity of the portion of chromosome 18q harbouring the $D C C$ gene, markedly reduced or absent DCC mRNA expression, aberrantly sized DCC transcripts, homozygous loss of $D C C$ and intragenic point mutations. ${ }^{10}$

Several studies have shown that alterations due to mutations in the simple repeat sequences or microsatellites are a feature in a number of cancers. ${ }^{11,12}$ Instability within these microsatellites was initially described by investigators studying colorectal cancers who observed that the length of microsatellite DNA in the tumour tissue varied from the matching 
normal tissue. This variation in the length of microsatellite repeats represents a mutational process of insertions or deletions within the tumour DNA. ${ }^{13}$

Nephroblastoma is the most common malignant renal tumour of childhood, with an incidence of approximately 1 in 10000 children worldwide. ${ }^{14}$ At our institution nephroblastoma is the most common solid paediatric tumour and a number of factors account for a poorer survival in our patients compared to patients from developed countries. These include poor nutritional status, intercurrent infection and advanced disease at presentation. ${ }^{15}$ The well-known prognostic determinants are histology and clinicopathological stage. In an earlier study, we identified a subset of patients that has a poor outcome despite having favourable histological features and low clinicopathological stage. As part of a larger study on tumour suppressor genes and cell adhesion molecules in nephroblastomas, we undertook the evaluation of allelic imbalance and microsatellite instability of the $D C C$ gene. A microsatellite study using fluorescent-based DNA technology investigating the $D C C$ gene in nephroblastomas has not been performed previously. This study was therefore conducted to determine whether mutations in the microsatellite sequences of the $D C C$ gene have any pathologic correlation or prognostic significance in nephroblastomas.

\section{Materials and methods}

\section{Cases}

In all, 106 cases of nephroblastomas were retrieved from the files of the Department of Pathology. They were obtained from nephrectomies performed over a period of 18 years from 1984 to 2001. Clinical data for all patients were available in the Department of Paediatric Surgery. Patients were managed according to International Society of Paediatric Oncology protocols, which include the administration of preoperative chemotherapy dependent on clinicopathological stage. Histological sections were reviewed to confirm the histological type and tumour staging parameters. For the purpose of this study, unfavourable histology nephroblastomas referred to the presence of diffuse anaplasia as described by Faria et al. ${ }^{16}$ Sections were then selected for DNA extraction. Normal DNA was extracted from normal renal tissue $(n=103)$ and normal lymph nodes $(n=3)$. Tissue blocks containing maximal tumour and minimal or no necrosis were selected for tumour DNA extraction. Contamination of tumour DNA by normal DNA was minimised by microdissecting the tumour. The haematoxylin \& eosin (H\&E) sections were evaluated under light microscopy and the normal and tumour tissue were marked out using a permanent marker. The marked H\&E slides were superimposed on the unstained tissue section and marked out on the reverse side using a permanent marker. Normal or tumour tissue was then scraped away from the glass slides using a sterile scalpel blade and transferred into separate $1.5 \mathrm{ml}$ Eppendorf tubes. This was followed by removal of the paraffin wax.

\section{DNA Extraction}

DNA was extracted from tissue using the standard proteinase $\mathrm{K}$ digestion and phenol/chloroform extraction method. ${ }^{17}$ The presence of amplifiable DNA was verified by polymerase chain reaction demonstration of the ubiquitous insulin gene ${ }^{18}$ (Figure 1).

\section{Cy5 Labelled Primers}

Cy5 labelled microsatellite primers (Roche Diagnostics, Mannheim, Germany) for the DCC gene were used (Table 1). Primer sequences were obtained from Boland et al ${ }^{19}$ and Liu et al. ${ }^{19,20}$ These primers were chosen for their high informativity rate.

\section{Polymerase Chain Reaction (PCR)}

The reactions were carried out in $200 \mu \mathrm{l}$ thin-walled PCR tubes. The total PCR volume was $25 \mu \mathrm{l}$, containing $10 \mathrm{pmol}$ of each Cy5 labelled primer pair, $2 \mu \mathrm{l}$ template DNA, $200 \mu \mathrm{M}$ dNTPs, $50 \mathrm{mM}$ PCR buffer containing $1.5 \mathrm{mM} \mathrm{MgCl}_{2}$, and $0.75 \mathrm{U}$ Taq DNA polymerase. The PCR amplification was performed using a Techne Progene thermocycler. The PCR reaction consisted of an initial denaturation step of $5 \mathrm{~min}$ at $95^{\circ} \mathrm{C}$. This was followed by 35 cycles, each cycle consisting of $1 \mathrm{~min}$ at $94^{\circ} \mathrm{C}, 30 \mathrm{~s}$ at $55^{\circ} \mathrm{C}$ (D18S21 and D18S58) or $58^{\circ} \mathrm{C}(\mathrm{D} 18 \mathrm{~S} 34)$, and $30 \mathrm{~s}$ at $72^{\circ} \mathrm{C}$. The final extension step was at $72^{\circ} \mathrm{C}$ for $7 \mathrm{~min}$.

\section{Polymerase Chain Reaction Product Preparation}

The microsatellite polymerase chain reaction products $(3 \mu \mathrm{l})$ were mixed with $3 \mu \mathrm{l}$ of STOP solution

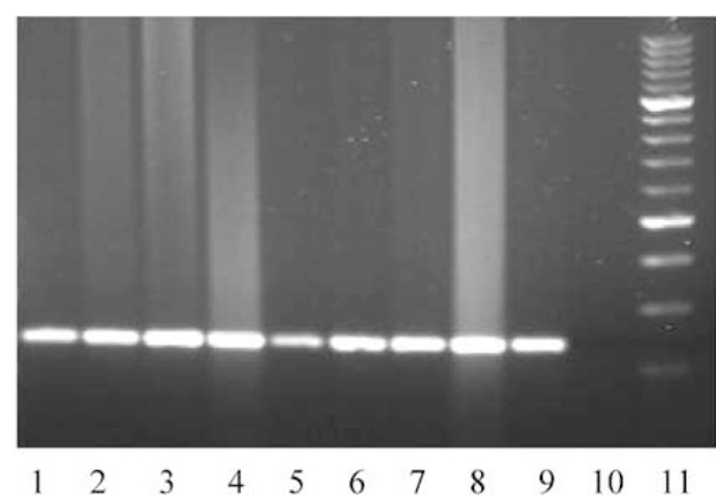
Lanes

Figure 1 A $2 \%$ agarose gel electrophoresis of DNA amplified across the exon 2 region of the insulin gene from formalin-fixed, paraffin wax-embedded sections of normal and tumour tissue. Lanes 1-8 contains PCR products of the amplified insulin fragment (size $236 \mathrm{bp}$ ). Lane 10 shows the negative control, and lane 9 shows the positive control. Lane 11 shows the molecular weight marker (100 bp ladder). 
(blue dextran 2000, deionized formamide; Pharmacia Biotech, Uppsala, Sweden) and denatured at $96^{\circ} \mathrm{C}$ for $3 \mathrm{~min}$ in a Techne Progene thermocycler. The samples were held on ice before being loaded on to the gel.

\section{Preparation of Size Markers}

The 50-500 base pair (bp) standard (Cy5 labelled) was used as the external size marker (Pharmacia Biotech).

\section{Automated DNA Fragment Analysis}

The microsatellite PCR products were analysed on the ALF Express Automated DNA Sequencer using a $6 \%$ Longranger sequencing gel (FMC Bioproducts, Rockland, ME, USA). The analysis was performed at $1500 \mathrm{~V}, 60 \mathrm{~mA}, 15 \mathrm{~W}$ and at a constant temperature of $55^{\circ} \mathrm{C}$. The data were analysed using the Fragment Manager software program.

\section{Calculation of Ratios for Allelic Imbalance}

The allele ratios were calculated by the method suggested by Canzian et al. ${ }^{21}$ The peak areas were expressed as ratios as follows: $(\mathrm{T} 2 \times \mathrm{N} 1) /(\mathrm{T} 1 \times \mathrm{N} 2)$, where T/N 1 and 2 are the first and second peaks of tumour and normal DNA, respectively. If the ratio was $<0.6$, then this was regarded as allelic imbalance with loss of the larger allele, and if the ratio was $>1.67$, then the smaller allele was lost.

\section{Microsatellite Instability}

The appearance of a novel allele in the tumour sample was interpreted as microsatellite instability. ${ }^{22}$

\section{Statistical Analysis}

The Statistical Package for Social Sciences software program (SPSS, Chicago, IL, USA) was employed for statistical analysis. Our results were correlated with age at diagnosis, preoperative chemotherapy, clinicopathological stage, histological classification and patient outcome. They were assessed by cross-tabulation and significance was determined by the $\chi^{2}$ test. Differences were considered significant at $P<0.05$.

\section{Results}

In all, 106 nephroblastomas were analysed. The overall follow-up ranged from 25 days to 14 years and 9 months. The patient age range was between 4 months and 14 years. The median age at diagnosis was 3 years old. In total, 19 patients had stage I disease, 28 had stage II, 26 had stage III and 33 were stage IV. There were two stage V patients who were further substaged as stage IV and stage I. Totally, 25 patients were alive, 44 had died and 37 patients were lost to follow-up. A total of 86 patients

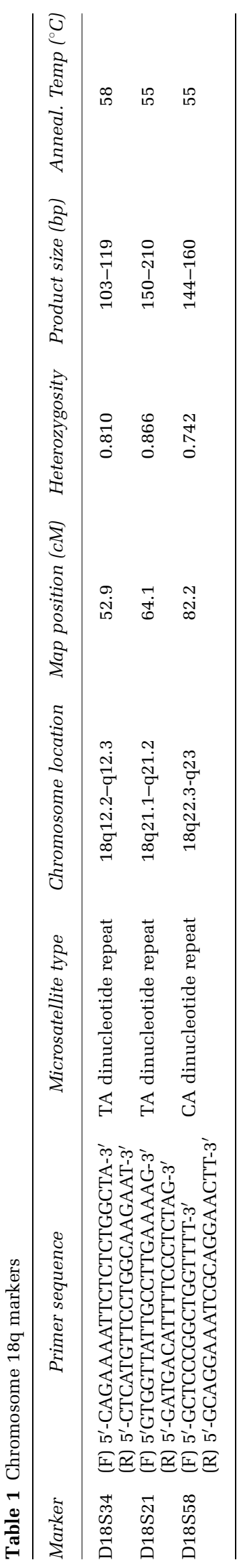


received preoperative chemotherapy according to the International Society of Paediatric Oncology protocol. There were 93 nephroblastomas with favourable histology (Figure 2a) and 13 with unfavourable histology (Figure 2b).

In this study, allelic imbalance/loss of heterozygosity at more than one microsatellite locus was found in 21 cases (20\%) (Figure 3). At the D18S21 locus, allelic imbalance/loss of heterozygosity was observed in 11 of 53 informative cases (21\%), at the D18S34 locus five of 23 cases $(22 \%)$, and at the D18S58 locus in eight of 42 cases (19\%). Microsatellite instability in the $18 \mathrm{q}$ region was seen in nine cases $(9 \%)$ in at least one of the three loci investigated (Table 2) (Figure 3).

To facilitate statistical analysis allelic imbalance/ loss of heterozygosity and microsatellite instability
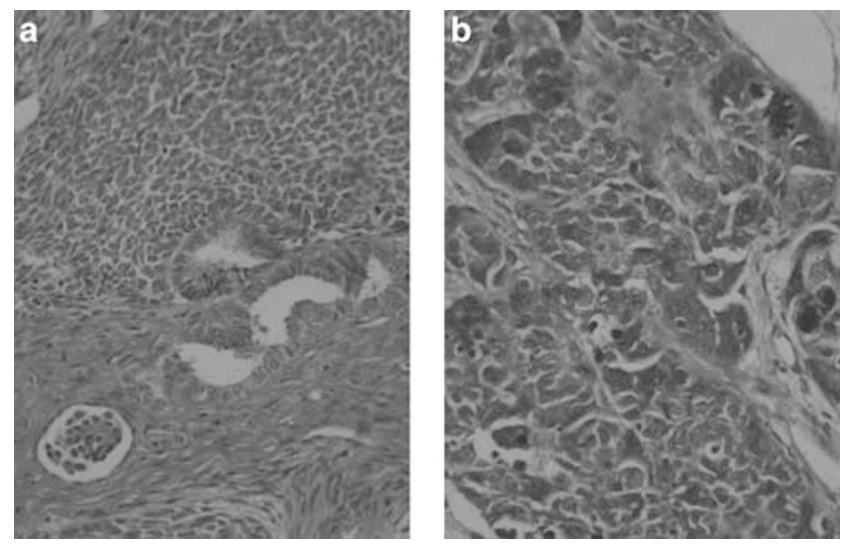

Figure 2 (a) Favourable histology nephroblastoma with blastema, epithelium and stroma. (b) Unfavourable histology nephroblastoma showing anaplastic features. were grouped together as 'genetic aberrations'. The cases that showed neither allelic imbalance/loss of heterozygosity nor microsatellite instability were designated 'no genetic aberrations' (Table 3).

There was a significant correlation between histological classification and genetic aberrations at the D18S34 locus $(P=0.027)$. In all, $23 \%$ of unfavourable histology tumours showed aberrations as compared to $3 \%$ of favourable histology tumours. The occurrence of allelic imbalance/loss of heterozygosity and microsatellite instability in the two histological types of nephroblastoma is shown in Table 4 .

The data were also grouped across all three markers so that if any case showed an aberration for any one or more of the three markers then that case was designated 'mutated'. The cases that showed no aberrations for any marker, fell in the 'no mutations' group. Of the 106 cases 27 showed mutations. In total, 21 of these cases showed mutations for at least one marker while the remaining six showed mutations for two markers. These 27 cases were then compared with the clinicopathological parameters.

Again histological classification appears to be a statistically significant variable $(P=0.012)$. Totally, $54 \%$ of unfavourable histology tumours were mutated compared to only $22 \%$ of favourable histology tumours (Table 5).

When the number of mutations (one vs two) was compared with histological classification, no statistically significant difference was apparent. However, a higher percentage of unfavourable histology tumours $(43 \%)$ showed more than one genetic mutation compared to favourable histology tumours $(15 \%)$. Also significant was that all the favourable histology tumours with two markers mutated had a
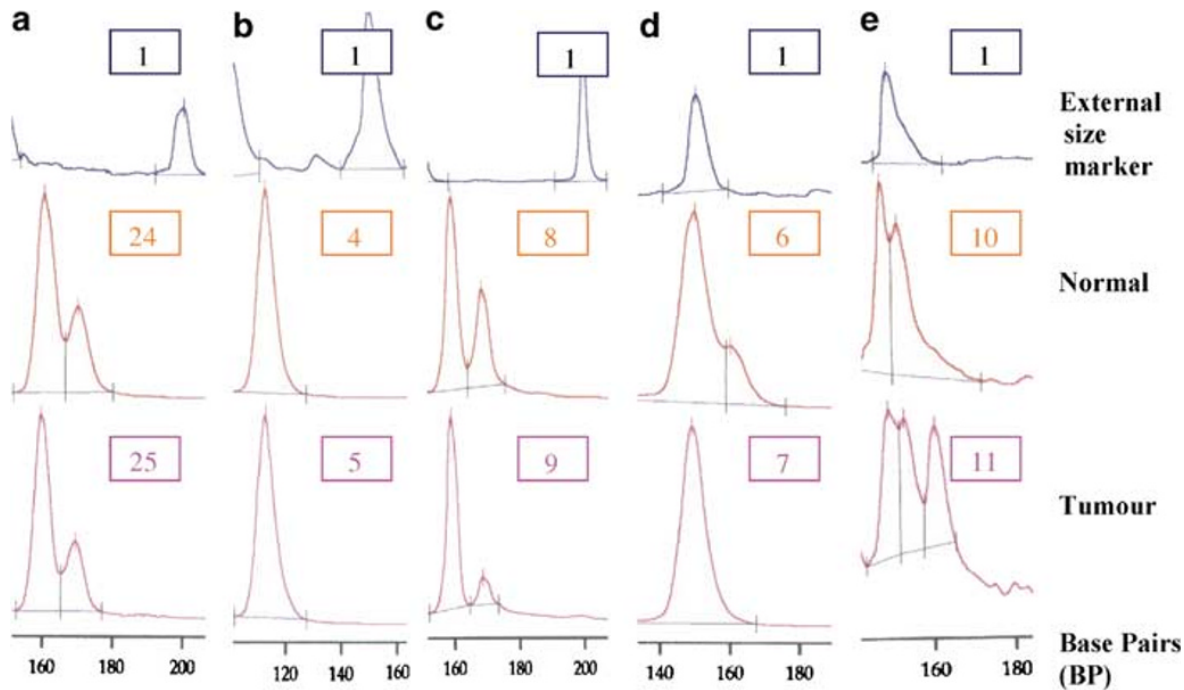

Figure 3 Assessment of allelic imbalance/loss of heterozygosity and microsatellite instability were based on electrophoretograms that were generated by the Fragment Manager Software. The appearance of two peaks in the normal and tumour (a) was reflective of a heterozygous or informative case (Marker D18S21), while the appearance of a single peak in both the normal and tumour tissue (b), Marker D18S34 was regarded as a homozygous or non-informative case. (c) Marker D18S58 shows a case displaying allelic imbalance $(R=1.93$ therefore the smaller allele is lost), (d) Marker D18S58 demonstrates loss of heterozygosity and (e) Marker D18S58 is an example of microsatellite instability. 
Table 2 Data generated for the three microsatellite markers

\begin{tabular}{lcccc}
\hline & D18S21 & D18S34 & D18S58 & Total no \% \\
\hline No change heterozygous & 36 & 17 & 32 & 64 \\
No change homozygous & 53 & 83 & 8 & 21 \\
Allelic imbalance/loss of heterozygosity & 11 & 1 & 106 & 9 \\
Microsatellite instability & 6 & 106 & $40 \%$ & 9 \\
Total cases & 106 & $22 \%$ & 50 \\
Informativity & $50 \%$ & &
\end{tabular}

Table 3 Genetic aberrations vs no genetic aberrations

\begin{tabular}{lccc}
\hline & $D 18 S 21$ & $D 18 S 34$ & $D 18 S 58$ \\
\hline Genetic Aberrations & 17 & 6 & 10 \\
No Genetic Aberrations & 89 & 100 & 96 \\
\hline
\end{tabular}

Table 4 Occurrence of allelic imbalance/loss of heterozygosity and microsatellite instability in the two histological types of nephroblastoma

$\begin{array}{ccc}\begin{array}{c}\text { Favourable } \\ \text { histology }\end{array} & \begin{array}{c}\text { Unfavourable } \\ \text { histology } \\ \text { (diffuse } \\ \text { anaplasia) }\end{array} & \text { Total } \\ & \end{array}$

\section{Marker D18S21}

Allelic imbalance/loss of heterozygosity

Microsatellite instability

Total

\section{8}

5

13

Marker D18S34

Allelic imbalance/loss of heterozygosity

Microsatellite instability

Total

$\begin{array}{lll}3 & 2 & 5 \\ 0 & 1 & 1 \\ 3 & 3 & 6\end{array}$

Marker D18S58

Allelic imbalance/loss of heterozygosity

Microsatellite Instability

Total

$\begin{array}{rrr}6 & 2 & 8 \\ 1 & 1 & 2 \\ 7 & 3 & 10\end{array}$

poor outcome similar to patients with unfavourable histology tumours $(P=0.016)$. All six patients with mutations for two markers died of disease, irrespective of histological classification or clinicopathological stage (Table 6).

There were no statistically significant findings when age at diagnosis was correlated with genetic aberrations, mutational status and the number of mutations per case (Table 7). Similarly, there was no significant difference in $18 \mathrm{q}$ mutations in those patients who received preoperative chemotherapy and those that did not. There was also no correlation between stage and 18q mutations.
Table 5 Distribution of mutated and not mutated vs histological classification

\begin{tabular}{lccr}
\hline & \multicolumn{2}{c}{ Histological classification } & \multirow{2}{*}{ Total } \\
\cline { 2 - 3 } & Favourable & Unfavourable & \\
\hline Mutated & $20(22 \%)$ & $7(54 \%)$ & 27 \\
Not Mutated & $73(78 \%)$ & $6(46 \%)$ & 79 \\
Total & 93 & 13 & 106 \\
\hline
\end{tabular}

\section{Discussion}

Tumour suppressor genes play an important role in a wide variety of cancer types and loss or inactivation of these genes result in cell cycle deregulation and neoplastic growth. Identification of regions of chromosome loss can serve as a guide to the location of tumour suppressor genes responsible for the development and/or progression of tumours. ${ }^{4}$ Allelic losses and reduced expression of the DCC gene were first identified in colon carcinoma. A role for $D C C$ in tumour progression has been well established by the large number of different tumour types that have reported deletions and/or reduced expression of $D C C .^{2-9}$ In addition, loss of the region housing the $D C C$ gene has also been associated with an increased likelihood of metastasis and death in a subset of patients with colorectal cancer. ${ }^{23}$

The most important known prognostic factors for nephroblastomas are histological classification and clinicopathological stage. Anaplastic or unfavourable histology nephroblastomas are associated with a poor prognosis due to the chemoresistance of the anaplastic tumour cells. These unfavourable histology tumours have been shown to harbour p53 mutations. ${ }^{24}$ Other genetic loci that have also been linked to adverse prognosis are $1 p, 7 p$ and $16 q .^{25,26}$ Functional studies show, in addition to $D C C$ being a tumour suppressor gene its protein product may function as a cell adhesion molecule. Cell adhesion molecules are surface receptors, which play critical roles during processes such as embryogenesis, thrombosis, wound healing, cell homing, immunoreactions, as well as tumour progression and metastasis. On the basis of its predicted amino-acid sequence the $D C C$ gene encodes a protein similar to the neural cell adhesion branch of the immunoglobulin superfamily and may participate with other proteins in cell-cell and cell-matrix interactions. 
Table 6 Distribution of the 27 cases showing mutations versus histological classification and outcome

\begin{tabular}{|c|c|c|c|c|c|c|}
\hline & \multirow[t]{2}{*}{ Total } & \multicolumn{2}{|c|}{ Histological Classification } & \multicolumn{3}{|c|}{ Outcome } \\
\hline & & Favourable & Unfavourable & Alive & Dead & Lost \\
\hline One Mutation & 21 & 17 & 4 & 6 & 9 & 6 \\
\hline Two Mutations & 6 & 3 (stages: $4,2,2$ ) & 3 (stages: $4,3,1$ ) & & 6 & \\
\hline Total & 27 & 20 & 7 & 6 & 15 & 6 \\
\hline
\end{tabular}

Table 7 Correlation of age at diagnosis with mutational status and the number of mutations

\begin{tabular}{|c|c|c|c|c|c|}
\hline & \multicolumn{4}{|c|}{ Age (in years) } & \multirow[t]{2}{*}{ Total } \\
\hline & $\leq 1$ & $1<A g e \leq 2$ & $2<A g e \leq 3$ & $>3$ & \\
\hline Mutated & 3 & 5 & 6 & 13 & 27 \\
\hline Not mutated & 10 & 23 & 17 & 29 & 79 \\
\hline $\begin{array}{l}\text { Total } \\
P=0.668\end{array}$ & 13 & 28 & 23 & 42 & 106 \\
\hline One mutation & 3 & 5 & 5 & 8 & 21 \\
\hline Two mutations & 0 & 0 & 1 & 5 & 6 \\
\hline $\begin{array}{l}\text { Total } \\
P=0.224\end{array}$ & 3 & 5 & 6 & 13 & 27 \\
\hline
\end{tabular}

The loss of chromosome 18q or downregulation of the DCC protein may influence cell adhesion properties through which cancer cells may acquire a more invasive and undifferentiated phenotype. ${ }^{23}$

Studies also show that the DCC gene product is a transmembrane receptor for netrin-1. Netrins act to both attract and repel the growing axons of a broad range of neuronal cell types during development and are also involved in controlling neuronal cell migration. Netrins are expressed in most adult tissues including many human cancer cell lines. The precise relationship between DCC and netrin has not been elucidated but evidence suggests that DCC may play a role in mediating directional cell migration within and outside the developing nervous system. Netrin-DCC signalling has also been shown to regulate cell death in epithelial cells in vitro. Speculation about the means by which loss of DCC function and netrin binding may influence the phenotype of cancer cells include the failure to recognize growth inhibitory or differentiation cues provided by netrins. Alterations in netrin binding may also directly promote alterations in cell migratory properties of cancer cells or their failure to respect tissue boundaries. Such effects may account for the apparently more aggressive and metastatic growth properties of cancer cells that have lost DCC expression. ${ }^{10,27}$

The present study reports the first comprehensive analysis of microsatellite instability and allelic imbalance/loss of heterozygosity of the DCC gene in nephroblastomas. D18S21 was the most informative locus. In addition, it displayed the most number of mutations followed by D18S58 and D18S34.
Allelic imbalance/loss of heterozygosity appears to be a more frequent aberration than microsatellite instability with $20 \%$ of cases showing allelic imbalance/loss of heterozygosity and only $9 \%$ of cases showing microsatellite instability.

We have found a significant association between 18q microsatellite aberrations and histological classification. The percentage of unfavourable histology tumours showing aberrations was higher than those tumours with favourable histology. Similarly, there was a significant correlation between $D C C$ aberrations and patient outcome. All patients with tumours showing aberrations for more than one DCC marker died, independent of histological classification and stage. Thus, the clinical relevance of the findings from this study suggests that the integrity of the $D C C$ locus is crucial and may be involved in conferring a poorer outcome when mutated. However, the mechanism by which this occurs is unknown and not necessarily related to decreased cell adhesion. The finding in this study that DCC aberrations independent of the other known prognostic factors is associated with adverse outcome, favours a prognostic role for molecular aberrations.

Although there was no statistically significant finding when age at diagnosis was correlated with mutational status and number of mutations, of interest was that the number of cases with mutations and the number of mutations observed per case increased with advancing age. This observation suggests that there is an association between the accumulation of genetic events and an advance in age. Furthermore, there appears to be a relationship between accumulation of genetic events and tumour progression. 
The informativity of the DCC markers demonstrated by this cohort was lower than that suggested. In two previous studies by our group conflicting informativity rates were observed. A study on 37 gastric tumours demonstrated a similar low informativity ${ }^{28}$ while another study on 32 colorectal tumours demonstrated a relatively higher informativity. ${ }^{29}$ Since baseline informativity rates have not been conducted for our population this difference may suggest that the same markers may not be suitable for all population groups and/or tumour types.

In conclusion, this study has shown that microsatellite instability of the $D C C$ locus is rare in nephroblastomas while allelic imbalance/loss of heterozygosity of the DCC locus is more frequent. Multiple aberrations involving the $D C C$ locus may play a role in the progression of nephroblastomas, and hence confer a poorer prognosis.

\section{Acknowledgements}

DG is a recipient of a research grant from the Cancer Association of South Africa.

\section{References}

1 Noffsinger A, Fenoglio-Preiser C. Evolution in concepts of the molecular pathogenesis of colon cancer. Adv Pathol Lab Med 1995;8:481-505.

2 Uchino S, Tsuda H, Noguchi M, et al. Frequent loss of heterozygosity at the DCC locus in gastric cancer. Cancer Res 1992;52:3099-3102.

3 Hohne M, Halatsch M, Kahl G, Weinel R. Frequent loss of expression of the potential tumour suppressor gene DCC in ductal pancreatic adenocarcinoma. Cancer Res 1992;52:2616-2619.

4 Pearlstein R, Benninger M, Carey T, et al. Loss of $18 \mathrm{q}$ predicts poor survival of patients with squamous cell carcinoma of the head and neck. Genes Chromosomes Cancer 1998;21:333-339.

5 Ho Y, Kalle W, Lo T, Lam W, Tang C. Reduced expression of $A P C$ and $D C C$ gene protein in breast cancer. Histopathology 1999;35:249-256.

6 Gao X, Honn K, Grignon D, Sakr W, Chen Y. Frequent loss of expression and loss of heterozygosity of the putative tumour suppressor gene $D C C$ in prostatic carcinomas. Cancer Res 1993;53:2723-2727.

7 Mikaye S, Nagai K, Yoshino K, Oto M, Endo M, Yuasa Y. Point mutations and allelic deletion of tumour suppressor gene DCC in human oesophageal squamous cell carcinomas and their relation to metastasis. Cancer Res 1994;54:3007-3010.

8 Reato G, Basso G, Putti M, Cignetti A, Guarini A, Foa R. Microsatellite analysis in childhood acute lymphoblastic leukemia. Haematologica 1998;83:403-407.

9 Hara A, Saegusa M, Mikami T, Okayasu I. Loss of DCC expression in astrocytomas: relationship to p53 abnormalities, cell kinetics and survival. J Clin Pathol 2001;54:860-865.

10 Cho R, Fearon E. DCC: linking tumour suppressor genes and altered cell surface interactions in cancer? Eur J Cancer 1995;31A:1055-1060.
11 Sturzeneker R, Bevilacqua R, Haddad L, Simpson A, Pena S. Microsatellite instability in tumours as a model to study the process of microsatellite mutations. Hum Mol Genet 2000;9:347-352.

12 Arzimangogou I, Gilbert F, Barber H. Microsatellite instability in human solid tumours. Cancer 1998;82:1808-1820.

13 Brentnall T. Microsatellite instability, shifting concepts in tumorigenesis. Am J Pathol 1995;147:561-563.

14 Coppes MJ, Haber DA, Grundy PE. Genetic events in the development of Wilms' tumor. N Engl J Med 1994;331:586-590.

15 Hadley G, Jacobs C. The clinical presentation of Wilms' tumour in black children. S Afr Med J 1990;77:565-567.

16 Faria P, Beckwith JB, Mishra K, et al. Focal versus diffuse anaplasia in Wilms tumor-New definitions with prognostic significance. Am J Surg Pathol 1996; 20:909-920.

17 Chetty R, Pulford K, Jones M. SCL/Tal-1 expression in T-acute lymphoblastic leukemia: an immunohistochemical and genotypic study. Hum Pathol 1995;26:994-998.

18 Olansky L, Janssen R, Willing C. Variability of the insulin gene in American Blacks with NIDDM. Diabetes 1992;41:742-749.

19 Boland C, Sato J, Appelman HD, Bresalier RS, Seinberg AP. Microallelotyping defines the sequence and tempo of allelic losses at tumour suppressor gene loci during colorectal cancer progression. Nat Med 1995;1:902-909.

20 Liu B, Farrington F, Petersen G. Genetic instability occurs in the majority of young patients with colorectal cancer. Nat Med 1995;1:348-352.

21 Canzian F, Salovaara R, Hemminki A. Semiautomated assessment of loss of heterozygosity and replication error in tumors. Cancer Res 1996;56:3331-3337.

22 Cawkwell L, Li D, Lewis F. Microsatellite instability in colorectal cancer: improved assessment using fluorescent polymerase chain reaction. Gastroenterology 1995;109:465-471.

23 Fearon E, Pierceall W. The deleted in colorectal cancer (DCC) gene: A candidate tumour suppressor gene encoding a cell surface protein with similarity to neural cell adhesion molecules. Cancer Surv 1995; 24:3-17.

24 Bardeesy N, Falkoff D, Petruzzi M, et al. Anaplastic Wilms' tumor, a subtype displaying poor prognosis, harbors p53 gene mutations. Nat Genet 1994;7:91-97.

25 Miozzo M, Perotti D, Minoletti F, et al. Mapping of a putative tumor suppressor locus to proximal $7 \mathrm{p}$ in Wilms tumors. Genomics 1996;37:310-315.

26 Grundy P, Telzerow P, Breslow N, Moksness J, Huff V, Paterson M. Loss of heterozygosity for chromosome $16 q$ and $1 p$ in Wilms' tumors predicts an adverse outcome. Cancer Res 1994;54:2331-2333.

27 Fearon E. DCC: is there a connection between tumorigenesis and cell guidance molecules? Biochim Biophys Acta 1996;1288:M17-M23.

28 Chetty R, Naidoo R, Tarin M, Sitti C. Chromosome 2p, $3 p 5 q$ and $18 q$ status in sporadic gastric cancer. Pathology 2002;34:275-281.

29 Naidoo R, Tarin M, Chetty R. A comparative microsatellite analysis of colorectal cancer in patients $<35$ years and $>50$ years of age. Am J Gastroenterol 2000;95:3266-3275. 